\title{
The risk of death within 5 years of first hospital admission in older adults
}

\author{
Kieran L. Quinn MD, Nathan M. Stall MD, Zhan Yao MSc, Therese A. Stukel PhD, Peter Cram MD, Allan S. Detsky \\ MD, Chaim M. Bell MD
}

Cite as: CMAJ 2019 December 16;191:E1369-77. doi: 10.1503/cmaj.190770

Visual abstract available at www.cmaj.ca/lookup/suppl/doi:10.1503/cmaj.190770/-/DC2

\begin{abstract}
BACKGROUND: The risk of death in people after their first admission to hospital or first presentation to the emergency department for any reason is not known. The objective of this study was to estimate the risk of death among older adults who had had no admissions to hospital or emergency department visits in the preceding 5 years.
\end{abstract}

METHODS: We used administrative data from Ontario, Canada, from 2007 to 2017 to measure the 5-year risk of death in community-dwelling adults aged 66 years and older after their first planned or unplanned hospital admission or emergency department visit, and among those who were neither admitted to hospital nor presented to the emergency department. We describe how this risk varied by age.

RESULTS: Among 922074 communitydwelling older adults, $12.7 \%$ died (116940 deaths) over a follow-up of 3112528 person-years (standardized mortality rate 53.8 per 1000 person-years). After the first unplanned hospital admission, 39.7\% died (59234 deaths, standardized mortality rate 127.6 per 1000 personyears). After the first planned hospital admission, $13.0 \%$ died (10 775 deaths, standardized mortality rate 44.6 per 1000 person-years). After the first visit to the emergency department, $10.9 \%$ died
(35663 deaths, standardized mortality rate 36.2 per 1000 person-years). Among those with neither an emergency department visit nor hospital admission during follow-up, 3.1\% died (11268 deaths, standardized mortality rate 29.6 per 1000 person-years). Slightly more than half of all deaths were in those with first unplanned hospital admission (50.7\%).

INTERPRETATION: Death within 5 years of first unplanned hospital admission for older adults is frequent and common. Knowledge of this risk may influence counselling and patient preferences and may be useful in research and analyses for health system planning.

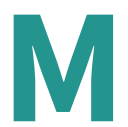

ore than 420 million hospital admissions occur every year around the world. ${ }^{1}$ Short-term prognosis is favourable; most people survive beyond admission. In North American adults, all-cause 1-year mortality after hospital admission ranges between $7 \%$ and $12 \% .^{2-5}$ Certain conditions have a less favourable long-term outcome. Notably, as many as threequarters of those admitted to hospital with heart failure do not live beyond 5 years. ${ }^{6,7}$ Only $5 \%$ of patients admitted to hospital with a new diagnosis of lung cancer are alive at 5 years. ${ }^{8}$ Several studies have measured mortality after a person's first hospital admission for specific conditions including cancer, heart failure, chronic obstructive pulmonary disease (COPD), pneumonia, myocardial infarction and atrial fibrillation. ${ }^{6-17}$ However, the risk of death after first hospital admission for any cause, or how the relationship between first hospital admission and mortality might change across age, is not known. This study addresses existing knowledge gaps by estimating the risk of death after a first acute care encounter in a population of previously healthy older adults cared for in Ontario, Canada. Other work has generally focused on short-term outcomes. Thus, this study aims to extend previous work by estimating the long-term risk of death across all health conditions and diagnoses among patients without previous hospital admission or emergency department visits at a population level.

Estimation of risk is important for many reasons. Providing patients or their families with risk estimates may help inform their care decisions. ${ }^{18}$ Health care teams may be prompted by the identification of elevated risk to engage in advance care planning discussions with their patients in order to provide care congruent with their expressed goals and wishes. ${ }^{19}$ Researchers use risk adjustment to account for differences between patients, which may influence health outcomes. Health care systems adjust for risk when evaluating facilities or clinicians, to account for potential differences in the patients they care for, which may 
also affect outcomes. Finally, health system planners may use analyses to track changes in risk over time to help organize health care delivery.

In light of these knowledge gaps and the importance of measuring risk, the objective of this study was to estimate the risk of death among older adults without any hospital admission or emergency department visit in the preceding 5 years. We measured the 5 -year risk of death after the first hospital admission or emergency department visit and describe how this risk varied by age.

\section{Methods}

\section{Study design, setting and data sources}

We conducted a population-based cohort study in Ontario, Canada, using linked clinical and health administrative databases between 2007 and 2017. Ontario is Canada's most populous province, containing about $25 \%$ of its population, with more than 13 million residents and 3 million adults older than 65 years. The administrative data sets used in this study were linked using unique encoded identifiers at the patient level and analyzed at ICES (Appendix 1, available at www.cmaj.ca/lookup/suppl/ doi:10.1503/cmaj.190770/-/DC1).

\section{Study cohort}

Our study cohort included all community-dwelling adults in Ontario aged 66 years and older who were alive at the cohort entry date on Apr. 1, 2007. We excluded people who presented to any emergency department or hospital in the 5 years before entry into the cohort, who were 100 years of age and older at cohort inception, who were nonresidents of Ontario, or who resided in a nursing home. Because we intended to include people who could access the health care system, we excluded those who had not seen a physician or who were not continuously enrolled in the provincial health insurance plan in the 5 years preceding cohort entry.

All residents of Ontario have publicly administered insurance for hospital care and medically necessary physicians' services, and those aged 65 years and older are provided publicly funded prescription drug insurance coverage for most drugs. We studied a cohort of older adults because the annual risk of death after any hospital admission substantially increases beyond the age of 70 years. ${ }^{4}$ Furthermore, conventional comorbidity indices rely on hospital records. Because our study included people without previous hospital admission, we were unable to use these comorbidity indices. By including those aged 66 years and older, we were able to use the total number of unique medications dispensed in the year before cohort entry as a measure of comorbidity. ${ }^{20,21}$

We determined the presence of diabetes and hypertension -2 of the most common chronic diseases in adults - using methods previously validated in the outpatient setting. ${ }^{22,23}$ We measured a person's access to the health care system by using the total number of physician visits in the year before their first hospital admission or presentation to the emergency department, including the total number of visits to their primary care and specialist physicians. People who were neither admitted to hospital nor presented to the emergency department were randomly assigned an index date for the purposes of determining their previous health care use.

\section{Index study date}

The index study date was a person's first hospital admission, presentation to the emergency department, or a randomly assigned date. ${ }^{6-10,16,17}$ People who were neither admitted to hospital nor presented to the emergency department required an index date to anchor the period in which to measure the study outcomes. Random assignment of an index date was the least biased method. For the purposes of this study, we defined "first hospital admission or emergency department visit" to mean the first such event to occur in 5 years; i.e., these individuals had not visited an emergency department or been admitted to a hospital in the 5 -year period before the index date. Within the cohort, people were assigned to 1 of 4 mutually exclusive groups: those with first unplanned (urgent) hospital admission, those with planned (elective) hospital admission, those with first presentation to the emergency department that did not result in hospital admission, and those who were neither admitted to hospital nor presented to the emergency department. We considered only admissions to acute care and nonpsychiatric facilities (e.g., medical rehabilitation) to define the index events.

\section{Outcomes}

The primary outcome was the risk of death from any cause over a 5 -year period. Reporting 5-year survival rates is useful in diseases that have shorter life expectancy after their diagnosis or a significant change in the disease trajectory, such as after hospital admission. Examples of such common diseases include certain types of cancer, heart failure and dementia. In all groups, we also measured the risk of death stratified by 5-year age intervals. ${ }^{4}$ We reported a person's cause of death and grouped it according to a modified form of Becker's leading cause of death. ${ }^{24}$

Secondary outcomes, which were intended to generate new hypotheses, included risk of death at 5 years using case-mix grouping to categorize admission diagnoses into those managed as a medical or surgical condition; the total number of emergency department visits, hospital admissions and admissions to the intensive care unit (ICU) for each group during the follow-up period; and risk of death at 5 years in a subset with noncancer diagnoses after their first unplanned hospital admission or visit to the emergency department (see Appendix 1, Table S4, for the complete list of diagnoses). We created the final set of these noncancer diagnoses by individually selecting the hospital admission or emergency department diagnoses that were in the top 100 most common reasons for hospital admission or emergency department presentation and carried the highest risk of death at 5 years for each care setting. We intentionally chose noncancer conditions, because many patients and health care providers may not recognize that some noncancer conditions, like dementia, are terminal. From our list, we excluded the diagnosis "palliative care," even though it was one of the most common reasons for hospital admission, because it does not indicate the specific medical condition responsible for the admission and because there are financial incentives for institutions to use it. ${ }^{25,26}$

People in the cohort were followed from the index date until death, 5 years, or Mar. 31, 2017 (whichever came first), at which point they were censored. 


\section{Statistical analysis}

We measured crude mortality rates after a person's first hospital admission or emergency department visit. We measured direct ageand sex-standardized mortality using the Ontario population in the year 2012 to control for differences in population structure and to provide a single summary measure that can be used to compare rates over time. We chose the year 2012 as it was the midpoint of our study period and used it to minimize any potential influences of secular changes on medical care and long-term mortality risk. We estimated time to death using a stratified Kaplan-Meier analysis.

We performed all analyses using SAS version 9.4 (SAS Institute, Cary, North Carolina).

\section{Ethics approval}

The use of data in this project was authorized under Section 45 of Ontario's Personal Health Information Protection Act and was approved by the research ethics board at Sinai Health System.

\section{Results}

\section{Baseline characteristics}

Of a total of 2942470 people aged 66 years and older, we excluded 2020396 from our study (68.9\%), 1736939 because they had been previously admitted to hospital or visited an emergency department in the preceding 5 years. The final cohort consisted of 922074 community-dwelling adults and represented $31.1 \%$ of the population of older adults in Ontario.

During the study period, there were 149107 people (16.2\%) with an unplanned first hospital admission, 82702 people $(8.9 \%)$ with a planned first hospital admission, 327164 people $(35.5 \%)$ who presented to the emergency department for their first time and were discharged home, and 363101 people (39.4\%) who were neither admitted to hospital nor presented to the emergency department (Figure 1).
In general, people were between 70 and 80 years of age, lived in urban areas, had hypertension, were prescribed 5 or more medications and had visited a physician several times over the preceding year (Table 1). People with a first unplanned hospital admission were slightly older than those in the other 3 groups, with higher rates of diabetes and hypertension. The overall level of comorbidity, as reflected by the number of medications prescribed, was similar across groups.

\section{Survival after first hospital admission or emergency department visit (primary outcome)}

There were 116940 deaths over 3112528 person-years of follow-up (crude mortality $12.7 \%$ of people). After the first unplanned hospital admission, crude mortality was $39.7 \%$ within 5 years (59234 deaths). After the first planned hospital admission, crude mortality was $13.0 \%$ (10775 deaths). After the first visit to the emergency department, crude mortality was $10.9 \%$ (35663 deaths). Among people who were neither admitted to hospital nor visited the emergency department, crude mortality was 3.1\% (11268 deaths) (Figure 2, Table 2). The standardized mortality rate among those with a first unplanned hospital admission was 3.5-fold higher than among people who presented to the emergency department and were not admitted to hospital, 2.9-fold higher than among people with a planned hospital admission and 4.3-fold higher than among people who were neither admitted to hospital nor visited the emergency department.

Of the 116940 deaths in the cohort, $50.7 \%$ occurred in people who had an unplanned hospital admission, $9.2 \%$ in people who had a planned hospital admission, $30.5 \%$ in those who had a first emergency department visit, and $9.6 \%$ in people who were neither admitted to hospital nor visited the emergency department during follow-up. Cancer and cardiovascular disease were the most common causes of death across all groups. The main admission diagnoses varied across groups (Appendix 1, Tables S1 and S2).

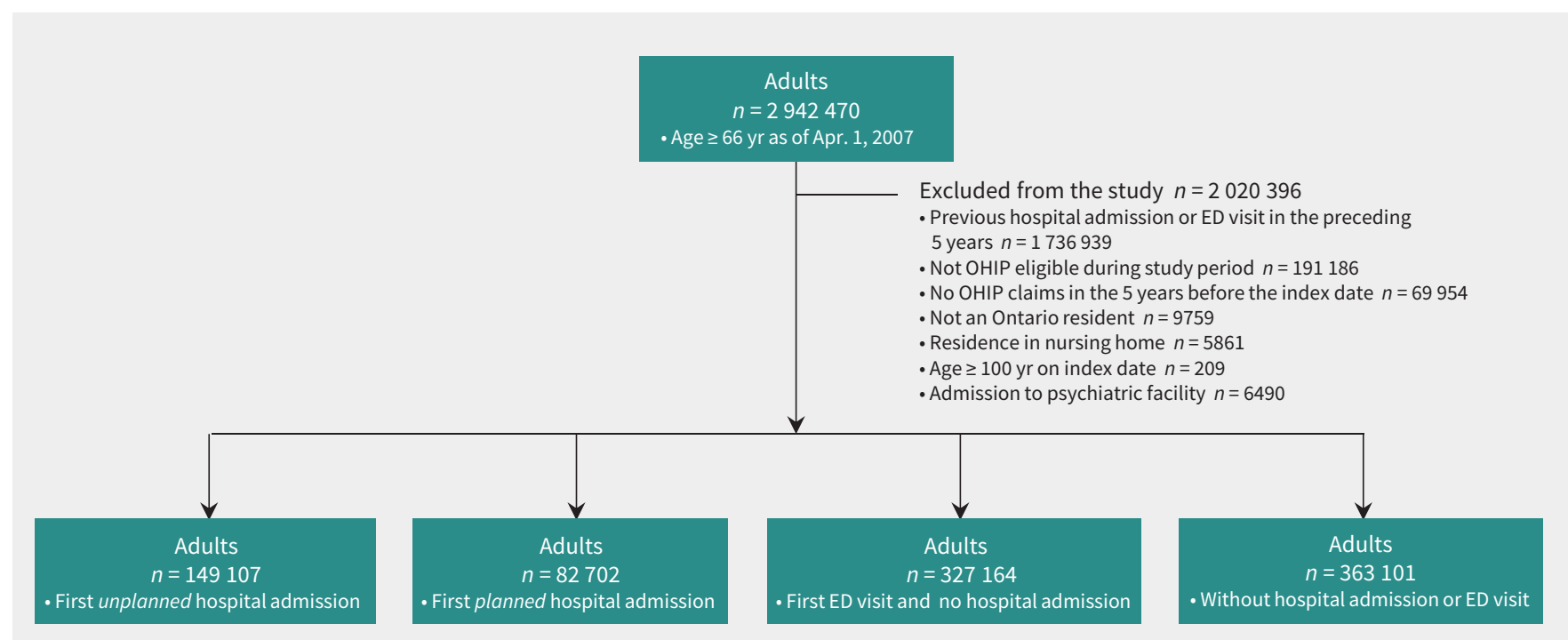

Figure 1: Flow diagram for the study sample. All community-dwelling adults aged 66 years or older as of Apr. 1, 2007, who had neither visited the emergency department (ED) nor been admitted to hospital in the preceding 5 years were included. The sample was divided hierarchically into 4 groups: first unplanned hospital admission, first planned hospital admission, first visit to the ED, and neither admission to the ED or to hospital. Note: OHIP = Ontario Health Insurance Plan. 
The absolute risk of death in all groups varied by age. Between the ages of 66 and 70 years, the risk of death was about 8-fold higher in people with a first unplanned hospital admission than in all other groups within the same age range (crude mortality $20 \%$ v. $2.5 \%$ ) (Figure 3). The risk of death increased by about
15\%-20\% per decade of life at hospital admission after a first unplanned admission. At 5 years post-admission, crude mortality was about $20 \%$ in people aged $66-70$ years compared with more than $60 \%$ in people aged $86-90$ years and $90 \%$ in people aged 96-100 years (Figure 3A).

Table 1 (part 1 of 2): Baseline characteristics of the study cohort (922 074 people)*

\begin{tabular}{|c|c|c|c|c|c|}
\hline Characteristic & $\begin{array}{l}\text { No. of people with } \\
\text { unplanned } \\
\text { hospital } \\
\text { admissions }(\%) \dagger \\
n=149107(16.2)\end{array}$ & $\begin{array}{c}\text { No. of people } \\
\text { with planned } \\
\text { hospital } \\
\text { admissions (\%) } \dagger \\
n=82702(8.9)\end{array}$ & $\begin{array}{l}\text { No. of people with } \\
\text { ED visit (\%) } † \\
n=327164(35.5)\end{array}$ & $\begin{array}{c}\text { No. of people with no } \\
\text { hospital admission or } \\
\text { ED visit (\%) } \dagger \\
n=363101(39.4)\end{array}$ & $\begin{array}{c}\text { Weighted } \\
\text { standardized } \\
\text { difference }\end{array}$ \\
\hline Age, yr, median (IQR) & $77(70-83)$ & $72(68-77)$ & $72(68-78)$ & $67(66-71)$ & $\begin{array}{l}0.56 \ddagger \\
0.46 \S \\
1.18 \uparrow\end{array}$ \\
\hline \multicolumn{6}{|l|}{ Age group, yr } \\
\hline $66-70$ & $38529(25.8)$ & $35028(42.4)$ & $138212(42.2)$ & $260591(71.8)$ & $\begin{array}{l}0.35 \\
0.35 \\
1.03\end{array}$ \\
\hline $71-75$ & $29689(19.9)$ & $22120(26.7)$ & $74573(22.8)$ & $50894(14.0)$ & $\begin{array}{l}0.16 \\
0.07 \\
0.16\end{array}$ \\
\hline $76-80$ & $29420(19.7)$ & $15232(18.4)$ & $55344(16.9)$ & $28234(7.8)$ & $\begin{array}{l}0.03 \\
0.07 \\
0.35\end{array}$ \\
\hline $81-85$ & $26364(17.7)$ & $7656(9.3)$ & $36031(11.0)$ & $14468(4.0)$ & $\begin{array}{l}0.25 \\
0.19 \\
0.45\end{array}$ \\
\hline $86-90$ & $16849(11.3)$ & $2270(2.7)$ & $17085(5.2)$ & $6038(1.7)$ & $\begin{array}{l}0.34 \\
0.22 \\
0.40\end{array}$ \\
\hline $91-95$ & $6767(4.5)$ & $365(0.4)$ & $4991(1.5)$ & $2197(0.6)$ & $\begin{array}{l}0.27 \\
0.18 \\
0.25\end{array}$ \\
\hline $96-100$ & $1489(1.0)$ & $31(0.0)$ & $928(0.3)$ & $679(0.2)$ & $\begin{array}{l}0.13 \\
0.09 \\
0.11\end{array}$ \\
\hline Female sex & $77500(52.0)$ & $40702(49.2)$ & $187423(57.3)$ & $197476(54.4)$ & $\begin{array}{l}0.06 \\
0.11 \\
0.05\end{array}$ \\
\hline \multicolumn{6}{|c|}{ Neighbourhood income quintile } \\
\hline 1 (lowest) & $29725(19.9)$ & $12255(14.8)$ & $57071(17.4)$ & $56335(15.5)$ & $\begin{array}{l}0.14 \\
0.06 \\
0.12\end{array}$ \\
\hline 2 & $31767(21.3)$ & $15617(18.9)$ & $65528(20.0)$ & $69448(19.1)$ & $\begin{array}{l}0.06 \\
0.03 \\
0.05\end{array}$ \\
\hline 3 & $28857(19.4)$ & $16278(19.7)$ & 64499 (19.7) & 70842 (19.5) & $\begin{array}{l}0.01 \\
0.01 \\
0.00\end{array}$ \\
\hline 4 & $29239(19.6)$ & $17939(21.7)$ & $67829(20.7)$ & 78691 (21.7) & $\begin{array}{l}0.05 \\
0.03 \\
0.05\end{array}$ \\
\hline 5 (highest) & $28987(19.4)$ & $20413(24.7)$ & $71230(21.8)$ & 86805 (23.9) & $\begin{array}{l}0.13 \\
0.06 \\
0.11\end{array}$ \\
\hline Missing & $532(0.4)$ & $200(0.2)$ & $1007(0.3)$ & $980(0.3)$ & $\begin{array}{l}0.02 \\
0.01 \\
0.02\end{array}$ \\
\hline
\end{tabular}


Table 1 (part 2 of 2): Baseline characteristics of the study cohort (922 074 people)*

\begin{tabular}{|c|c|c|c|c|c|}
\hline Characteristic & $\begin{array}{l}\text { No. of people with } \\
\text { unplanned } \\
\text { hospital } \\
\text { admissions }(\%) \dagger \\
n=149107(16.2)\end{array}$ & $\begin{array}{l}\text { No. of people } \\
\text { with planned } \\
\text { hospital } \\
\text { admissions (\%)† } \\
n=82702(8.9)\end{array}$ & $\begin{array}{l}\text { No. of people with } \\
\text { ED visit (\%) } \dagger \\
n=327164(35.5)\end{array}$ & $\begin{array}{c}\text { No. of people with no } \\
\text { hospital admission or } \\
\text { ED visit (\%)† } \\
n=363101(39.4)\end{array}$ & $\begin{array}{l}\text { Weighted } \\
\text { standardized } \\
\text { difference }\end{array}$ \\
\hline \multicolumn{6}{|l|}{ Geographic location } \\
\hline Urban & $135252(90.7)$ & $74285(89.8)$ & $287538(87.9)$ & 331677 (91.3) & $\begin{array}{l}0.03 \\
0.09 \\
0.02\end{array}$ \\
\hline Missing & $24(0.0)$ & $6(0.0)$ & $27(0.0)$ & $16(0.0)$ & $\begin{array}{l}0.01 \\
0.01 \\
0.01\end{array}$ \\
\hline Diabetes & $45182(30.3)$ & $21287(25.7)$ & $79033(24.2)$ & $80394(22.1)$ & $\begin{array}{l}0.10 \\
0.14 \\
0.19\end{array}$ \\
\hline Hypertension & 110245 (73.9) & $58793(71.1)$ & 211349 (64.6) & $197562(54.4)$ & $\begin{array}{l}0.06 \\
0.20 \\
0.42\end{array}$ \\
\hline \multicolumn{6}{|l|}{ No. of medications } \\
\hline 0 & $12089(8.1)$ & $3034(3.7)$ & $28616(8.7)$ & $66725(18.4)$ & $\begin{array}{l}0.19 \\
0.02 \\
0.31\end{array}$ \\
\hline 1 & $8048(5.4)$ & $4233(5.1)$ & $25209(7.7)$ & $40612(11.2)$ & $\begin{array}{l}0.01 \\
0.09 \\
0.21\end{array}$ \\
\hline 2 & $9627(6.5)$ & $5903(7.1)$ & 29668 (9.1) & 42257 (11.6) & $\begin{array}{l}0.03 \\
0.10 \\
0.18\end{array}$ \\
\hline 3 & $10748(7.2)$ & $6891(8.3)$ & $31248(9.6)$ & $37989(10.5)$ & $\begin{array}{l}0.04 \\
0.08 \\
0.11\end{array}$ \\
\hline 4 & $11612(7.8)$ & $7,906(9.6)$ & $31605(9.7)$ & 34588 (9.5) & $\begin{array}{l}0.06 \\
0.07 \\
0.06\end{array}$ \\
\hline$\geq 5$ & $96983(65.0)$ & $54735(66.2)$ & $180818(55.3)$ & $140930(38.8)$ & $\begin{array}{l}0.02 \\
0.20 \\
0.54\end{array}$ \\
\hline Has primary care physician & 142210 (95.4) & 81757 (98.9) & 318407 (97.3) & 342147 (94.2) & $\begin{array}{l}0.16 \\
0.09 \\
0.08\end{array}$ \\
\hline \multicolumn{6}{|c|}{ Health care system use in yr. before cohort entry } \\
\hline $\begin{array}{l}\text { No. physician visits, } \\
\text { median (IQR) }\end{array}$ & $11(6-18)$ & $18(13-24)$ & $9(5-14)$ & $6(3-10)$ & $\begin{array}{l}0.60 \\
0.26 \\
0.96\end{array}$ \\
\hline $\begin{array}{l}\text { No. primary care } \\
\text { physician visits, median } \\
\text { (IQR) }\end{array}$ & $6(3-10)$ & $6(4-10)$ & $5(3-8)$ & $3(1-6)$ & $\begin{array}{l}0.76 \\
0.18 \\
0.96\end{array}$ \\
\hline $\begin{array}{l}\text { No. specialist visits, } \\
\text { median (IQR) }\end{array}$ & $4(1-8)$ & $11(7-15)$ & $3(1-6)$ & $2(0-4)$ & $\begin{array}{l}0.53 \\
0.25 \\
0.94\end{array}$ \\
\hline $\begin{array}{l}\text { Died during hospital } \\
\text { admission or in the ED }\end{array}$ & $13080(8.8)$ & $533(0.6)$ & $1931(0.6)$ & - & $\begin{array}{c}0.39 \\
0.39 \\
-\end{array}$ \\
\hline \multicolumn{6}{|c|}{$\begin{array}{l}\text { Note: } E D=\text { emergency department, IQR = interquartile range. } \\
\text { `Baseline characteristics of community-dwelling adults age } \geq 66 \text { years with first hospital admission, ED visit, or neither, residing in Ontario, Canada, between } 2007 \text { and } 2016 \text {. } \\
\text { †Unless stated otherwise. } \\
\text { tWeighted standardized differences for unplanned hospital admission versus planned hospital admission. } \\
\text { §Weighted standardized differences for unplanned hospital admission versus ED visit. } \\
\text { IWeighted standardized differences for unplanned hospital admission versus no hospital admission or ED visit. }\end{array}$} \\
\hline
\end{tabular}




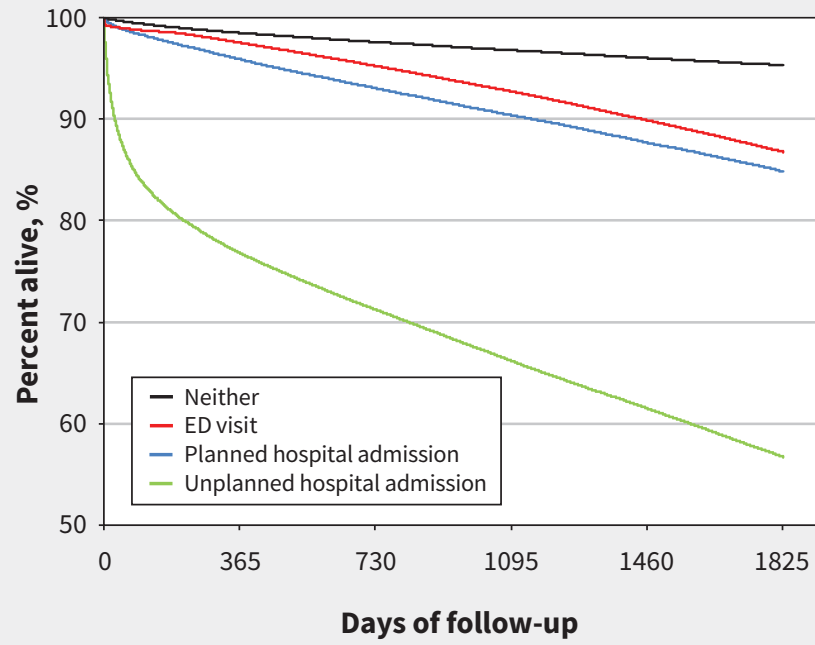

Figure 2: Survival by study group. Survival after a first hospital admission, emergency department (ED) visit or neither in community-dwelling adults aged $\geq 66$ years in Ontario, Canada, between 2007 and 2016. The percent alive has been truncated on the figure to $50 \%$.

\section{Condition-specific mortality and subsequent health care use (secondary outcomes)}

After a first unplanned hospital admission, male sex, high income and people whose main admission diagnosis was managed as a medical condition as determined by case-mix grouping had a higher risk of death at 5 years than those whose main admission diagnosis was managed as a surgical condition (Appendix 1, Figures S2-S4).

Among those with a first unplanned hospital admission, the subset of selected noncancer conditions were the main admission diagnoses in 56195 ( $n=149$ 107; 37.7\%) people; 20284 (crude mortality $36.1 \%$ ) people with these diagnoses died within 5 years. Among those with their first emergency department visit, noncancer diagnoses were the main reason for visiting the emergency department in $67723(n=327166 ; 20.7 \%)$ people. The 5 -year crude mortality was $11.7 \%$ (7953/67 723) (Appendix 1, Figure S5).

People with a first unplanned hospital admission had a higher number of subsequent admissions to hospital (median 1, interquartile range [IQR] 0-2) than those with a first planned hospital admission (median 0, IQR 0-1), emergency department visit (median 0, IQR 0-1), or with neither (median 0, IQR 0-0), but had a similar number of emergency department visits and ICU admissions (Appendix 1, Table S3).

\section{Interpretation}

Our population-based study of more than 900000 communitydwelling older adults found that almost $40 \%$ of people died in the 5 years after their first unplanned hospital admission, which accounted for half of all deaths. We used 3 comparator groups to determine the magnitude of our findings and found that people with an unplanned hospital admission had a substantially higher risk of death. The standardized mortality rate among those with a first unplanned hospital admission was also considerably higher than in all other groups and compared with Ontario's population in 2012. Compared with the general population, the mortality rate was nearly 5 -fold higher. ${ }^{27}$ Finally, we found that the risk of death increased with age across all groups, but the discrepancy across the 4 groups was largest for the youngest age category.

Our study adds to current knowledge about risk of death after hospital admission. Previous studies report similar short-term risk of death after any hospital admission in older adults, many of whom had been previously admitted to hospital. In a prospective study of 2922 adults older than 70 years, mortality at 1 year after hospital admission ranged from $13 \%$ to $68 \%$, and mortality was associated with the patient's age, level of functioning and the presence of metastatic cancer. ${ }^{2}$ In a separate cohort study of more than 3 million hospital admissions in North America, the

Table 2: Age- and sex-standardized mortality rates by exposure group (922 074 people)*

\begin{tabular}{|c|c|c|c|c|}
\hline $\begin{array}{l}\text { Mortality } \\
\text { measure }\end{array}$ & $\begin{array}{c}\text { Unplanned } \\
\text { hospital } \\
\text { admission } \\
n=149107 \\
(16.2 \%)\end{array}$ & $\begin{array}{l}\text { Planned hospital } \\
\text { admission } \\
n=82702 \\
(8.9 \%)\end{array}$ & $\begin{array}{c}\text { ED visit } \\
n=327164 \\
(35.5 \%)\end{array}$ & $\begin{array}{c}\text { No hospital admission } \\
\text { or ED visit } \\
n=363101(39.4 \%)\end{array}$ \\
\hline \multicolumn{5}{|c|}{ Standardized mortality, \%† } \\
\hline 5-year & 36.8 & 16.4 & 13.5 & 8.3 \\
\hline 1-year & 21.6 & 5.3 & 3.1 & 4.3 \\
\hline 30-day & 9.5 & 1.2 & 1.2 & 0.8 \\
\hline In-hospital & 8.0 & 0.8 & 0.7 & - \\
\hline \multicolumn{5}{|c|}{ Standardized mortality rate† (per 1000 person-years) } \\
\hline 5-year & 127.6 & 44.6 & 36.2 & 29.6 \\
\hline
\end{tabular}


overall risk of death within 1 year of admission was $8.7 \%$, which increased with age and previous comorbidity. ${ }^{5}$ Finally, in a cohort study of more than 35 million hospital admissions between 1994 and 2009, death within 1 year of hospital admission ranged between $9.2 \%$ and $11.6 \%$. In that study, adults older than 65 years had an associated 6- to 25-fold increased odds of death compared with adults aged 20-25 years. ${ }^{4}$ None of these studies measured the risk of death after a first hospital admission (none of the patients in our study had been admitted in the previous 5 years) in a cohort of older adults. Therefore, the findings from these studies may be heavily influenced by patients with multiple comorbidities and repeated hospital admissions, and do not directly apply to a population of healthier people like those in our study.

Earlier studies report a similar risk of death to our study after a person's first hospital admission for a specific condition such as heart failure or COPD. A cohort study of 9943 older adults (mean age $76 \mathrm{yr}$ ) who were newly admitted to hospital with a diagnosis of heart failure found that the 5-year mortality rate was $69 \% .{ }^{6}$ In a cohort study of 4204 older adults (mean age $75 \mathrm{yr}$ ) with their first hospital admission for COPD, 1-year mortality was $22 \% .{ }^{10}$ One of our secondary outcomes provides further evidence of
A

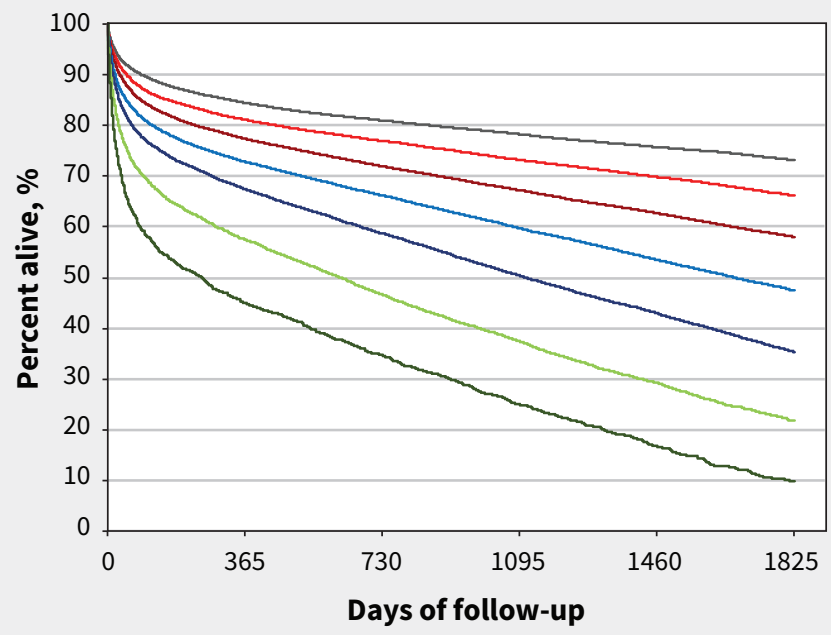

C

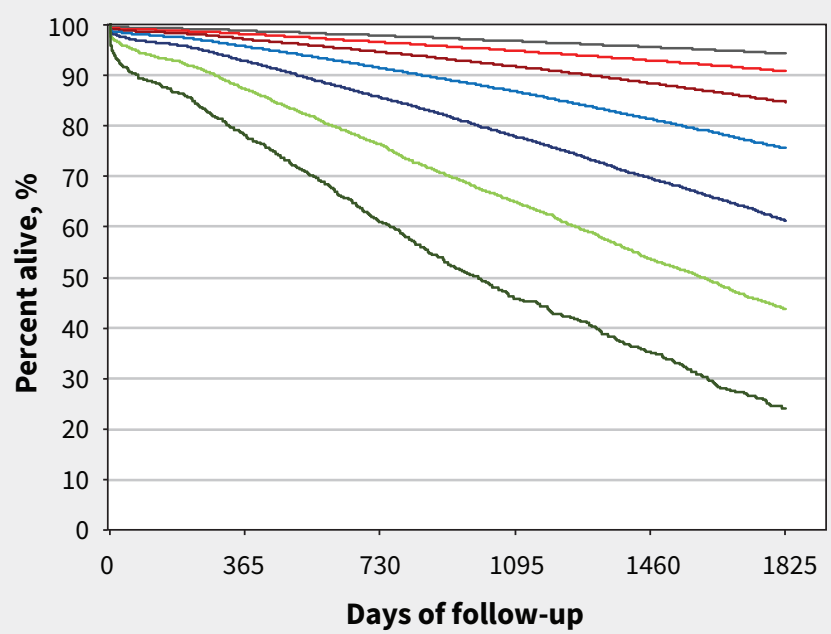

B

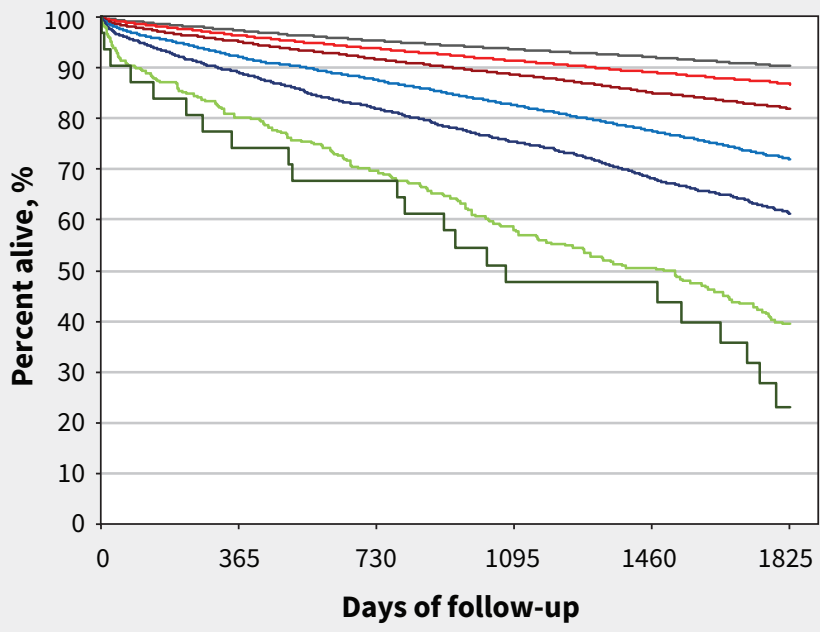

D

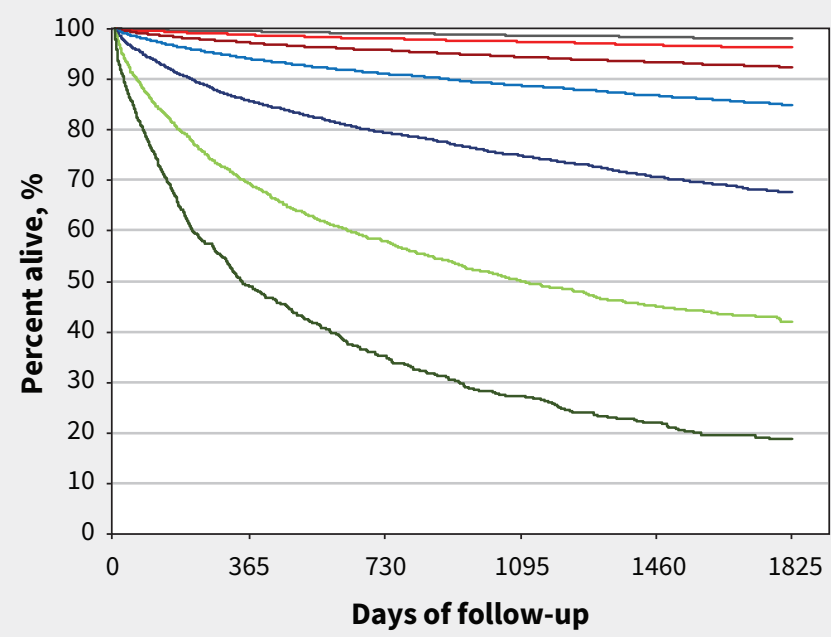

$$
-66-70 \quad-71-75 \quad-76-80 \quad-81-85 \quad-86-90 \quad-91-95 \quad-96-100
$$

Figure 3: Survival by age and study group. Survival stratified by 5-year age intervals after (A) a first unplanned hospital admission, (B) planned hospital admission, (C) emergency department visit, or (D) neither ("population control") in community-dwelling adults aged 66 years or older in Ontario, Canada, between 2007 and 2016. 
long-term survival at a population level in people with a first hospital admission or emergency department visit, and for people with a subset of important noncancer diagnoses.

We believe there are 4 main applications of our findings. First, estimation of risk and its communication are important because it allows patients, their families and their physicians to make better-informed decisions for their care. ${ }^{18}$ In a population of healthier people without previous use of acute care, unexpected hospital admission should be recognized as a sentinel event that likely signifies an increased risk of death in the long term. Recognition of this risk may trigger important discussions among patients, caregivers and health care providers about health preferences for future care. The American Medical Association encourages advance care planning for all people, regardless of age or health status. ${ }^{28}$ However, this has been challenging to achieve at a population level, with previous research showing that less than $50 \%$ of high-risk patients had completed advanced care planning..$^{29}$ Our data highlight an important group of people with whom these conversations should occur, which may be an efficient initial strategy to ensure patients receive the care they want when resources are limited. ${ }^{30}$ Second, our data provide a baseline population-level risk, to be adjusted upward or downward with the addition of more granular information on an individual patient's comorbidities, functional and socioeconomic status - an exercise that most clinicians are comfortable performing for their patients. Third, health services researchers commonly use risk adjustment to account for potential differences in study populations, which may affect measured health outcomes. First hospital admission in 5 years may be an important element of risk adjustment in future studies of older adults. Fourth, health care systems may also track rates of death after first hospital admission over time to inform the organization of health care delivery needs if those rates change.

\section{Limitations}

Our study has limitations. We do not explain why all people especially those admitted with nonterminal diseases such as urinary tract infection - were at increased risk of death in the long term. Conversely, the substantial early mortality related to people admitted for sepsis (Appendix 1 ) may be a reflection of the methods chosen to identify it, as previous studies have shown wide variation in the accuracy of various algorithms to detect sepsis. ${ }^{31}$ These secondary outcomes were meant to be hypothesis generating and require further investigation. Although we were able to report the most common causes of death and show that health care use was increased after first admission to hospital, these events are not necessarily causal. By design, patients in our study cohort had not come in contact with acute care settings in the previous 5 years, which limited our ability to detect important comorbid conditions that often rely on International Classification of Diseases coding derived from these data sets. We intentionally did not perform statistical adjustment for potential confounders because we felt this would not provide valid estimates of mortality risk when directly comparing such clinically heterogeneous groups of individuals. For example, adjusting for the presence of cardiovascular conditions as a group would include combined adjustment for both heart failure and acute coronary syndrome, 2 conditions with significantly different 5-year mortality rates. This issue exists across each organ system where the range of clinical conditions and their corresponding mortality rates are too diverse to combine for adjustment.

We excluded some people based on the assumption that they were unable to reliably access health care if they had not previously seen a physician, which may bias the results, or they were not continuously enrolled in the provincial health insurance plan and therefore lacked the data necessary for their outcomes to be measured. However, it is also possible that they chose not to access health care or were well enough not to need it.

Finally, our results may not be generalizable to other jurisdictions with different population demographics, health delivery systems and thresholds for hospital admission.

\section{Conclusion}

Hospital admission is common but may not be recognized as an indicator of long-term risk of death. Nearly $40 \%$ of older adults with a first unplanned hospital admission die within 5 years regardless of the reason for admission. This information may be useful to patients, clinicians, researchers and health system planners. Our hope is that this simple information can inform complex health care decisions.

\section{References}

1. 10 facts on patient safety. Geneva: World Health Organization; 2019. Available: www.who.int/features/factfiles/patient_safety/en/ (accessed 2019 Jan. 23).

2. Walter LC, Brand RJ, Counsell SR, et al. Development and validation of a prognostic index for 1-year mortality in older adults after hospitalization. JAMA 2001;285:2987-94.

3. Jencks SF, Williams MV, Coleman EA. Rehospitalizations among patients in the Medicare fee-for-service program. N Engl J Med 2009;360:1418-28.

4. van Walraven C. Trends in 1-year survival of people admitted to hospital in Ontario, 1994-2009. CMAJ 2013;185:E755-62.

5. van Walraven C, McAlister FA, Bakal JA, et al. External validation of the Hospitalpatient One-year Mortality Risk (HOMR) model for predicting death within 1 year after hospital admission. CMAJ 2015;187:725-33.

6. Ko DT, Alter DA, Austin PC, et al. Life expectancy after an index hospitalization for patients with heart failure: a population-based study. Am Heart J 2008;155:324-31.

7. Lassus JPE, Siirilä-Waris K, Nieminen MS, et al.; FINN-AKVA study group. Long-term survival after hospitalization for acute heart failure - differences in prognosis of acutely decompensated chronic and new-onset acute heart failure. Int J Cardiol 2013;168:458-62.

8. Stewart S, MacIntyre K, Hole DJ, et al. More "malignant" than cancer? Five-year survival following a first admission for heart failure. Eur J Heart Fail 2001;3:315-22.

9. Ahmed A, Allman RM, Fonarow GC, et al. Incident heart failure hospitalization and subsequent mortality in chronic heart failure: a propensity-matched study. J Card Fail 2008;14:211-8.

10. Ho T-W, Tsai Y-J, Ruan S-Y, et al.; HINT Study Group. In-hospital and one-year mortality and their predictors in patients hospitalized for first-ever chronic obstructive pulmonary disease exacerbations: a nationwide population-based study. PLoS One 2014;9:e114866.

11. Olsson LG, Swedberg K, Lappas G, et al. Trends in mortality after first hospitalization with atrial fibrillation diagnosis in Sweden 1987 to 2006. Int J Cardiol 2013;170:75-80.

12. Rasmussen S, Zwisler A-D, Abildstrøm S, et al. Hospital variation in mortality after first acute myocardial infarction in Denmark from 1995 to 2002: lower short-term and 1-year mortality in high-volume and specialized hospitals. Med Care 2005;43:970-8.

13. Säynäjäkangas $\mathrm{O}$, Lampela $\mathrm{P}$, Koiranen $\mathrm{M}$, et al. Mortality after first hospitalization for chronic obstructive pulmonary disease: changes in 1980-1998. Cent Eur J Public Health 2004;12:19-20. 
14. Søgaard OS, Lohse N, Gerstoft J, et al. Mortality after hospitalization for pneumonia among individuals with HIV, 1995-2008: a Danish cohort study. PLoS One 2009;4:e7022.

15. Sun A, Netzer G, Small DS, et al. Association between index hospitalization and hospital readmission in sepsis survivors. Crit Care Med 2016;44:478-87.

16. Vaartjes I, Hoes AW, Reitsma JB, et al. Age- and gender-specific risk of death after first hospitalization for heart failure. BMC Public Health 2010; 10:637.

17. Vanasse A, Courteau J, Couillard S, et al. Predicting one-year mortality after a "first" hospitalization for chronic obstructive pulmonary disease: an eight-variable assessment score tool. COPD 2017;14:490-7.

18. Ahmed H, Naik G, Willoughby $\mathrm{H}$, et al. Communicating risk. BMJ 2012;344: e3996.

19. You JJ, Downar J, Fowler RA, et al.; Canadian Researchers at the End of Life Network. Barriers to goals of care discussions with seriously ill hospitalized patients and their families: a multicenter survey of clinicians. JAMA Intern Med 2015; 175:549-56

20. Schneeweiss S, Wang PS, Avorn J, et al. Improved comorbidity adjustment for predicting mortality in Medicare populations. Health Serv Res 2003;38: 1103-20.

21. Bell CM, Bajcar J, Bierman AS, et al. Potentially unintended discontinuation of longterm medication use after elective surgical procedures. Arch Intern Med 2006;166:2525-31.

22. Tu K, Chen Z, Lipscombe LL; Canadian Hypertension Education Program Outcomes Research Taskforce. Prevalence and incidence of hypertension from 1995 to 2005: a population-based study. CMAJ 2008;178:1429-35.
23. Hux JE, Ivis F, Flintoft V, et al. Diabetes in Ontario: determination of prevalence and incidence using a validated administrative data algorithm. Diabetes Care 2002;25:512-6.

24. Becker R, Silvi J, Fat DM, et al. A method for deriving leading causes of death. Bull World Health Organ 2006;84:297-304.

25. Chong CA, Nguyen GC, Wilcox ME. Trends in Canadian hospital standardised mortality ratios and palliative care coding 2004-2010: a retrospective database analysis. BMJ Open 2012;2:e001729.

26. Downar J, Sibbald R, Lazar NM. Ethical considerations for classifying patients as "palliative" when calculating Hospital Standardised Mortality Ratios. J Med Ethics 2010;36:387-90.

27. Shumanty R. Report on demographic situation in Canada: Mortality - Overview, 2004 to 2016. Ottawa: Statistics Canada; 2018, modified 2018 June 28. Available: www150.statcan.gc.ca/n1/pub/91-209-x/2018001/article/54957-eng.htm (accessed 2019 Feb. 28).

28. Ethics: advance care planning - Code of Medical Ethics Opinion 5.1. Chicago: American Medical Association. Available: www.ama-assn.org/delivering-care/ ethics/advance-care-planning (accessed 2019 May 8).

29. Heyland DK, Barwich D, Pichora D, et al.; ACCEPT (Advance Care Planning Evaluation in Elderly Patients) Study Team; Canadian Researchers at the End of Life Network (CARENET). Failure to engage hospitalized elderly patients and their families in advance care planning. JAMA Intern Med 2013;173:778-87.

30. Houben CHM, Spruit MA, Groenen MTJ, et al. Efficacy of advance care planning: a systematic review and meta-analysis. J Am Med Dir Assoc 2014;15:477-89.

31. Jolley RJ, Sawka KJ, Yergens DW, et al. Validity of administrative data in recording sepsis: a systematic review. Crit Care 2015;19:139.

\section{Competing interests: None declared.}

This article has been peer reviewed.

Affiliations: Department of Medicine (Quinn, Stall, Cram, Detsky, Bell), University of Toronto; ICES Central (Yao, Stukel); Institute of Health Policy, Management and Evaluation (Quinn, Stall, Stukel, Cram, Detsky, Bell), University of Toronto, Toronto, Ont.

Contributors: All of the authors contributed to the conception and design of the work. Zhan Yao was responsible for the acquisition of data and also analyzed it, along with Kieran Quinn. All of the authors interpreted the data. All of the authors drafted the manuscript, revised it critically for important intellectual content, gave final approval of the version to be published and agreed to be accountable for all aspects of the work.

Funding: This study was funded by a Physician Services Incorporated Resident Research Grant, and by the Sinai Health System Research Foundation Fund. Kieran Quinn and Nathan Stall receive funding from the Canadian Institutes of Health Research Vanier Scholarship Program, the Eliot Phillipson Clinician-Scientist Training Program and the Clinician Investigator Program at the University of Toronto. Peter Cram holds grant funding from the US National Institutes of Health.
Data sharing: The data set from this study is held securely in coded form at ICES. While data-sharing agreements prohibit ICES from making the dataset publicly available, access may be granted to those who meet prespecified criteria for confidential access, available at www.ices.on.ca/DAS. The full data set creation plan and underlying analytic code are available from the authors upon request, understanding that the programs may rely upon coding templates or macros that are unique to ICES.

Disclaimer: Nathan Stall is an associate editor for CMAJ and was not involved in the editorial decision-making process for this article. This study was supported by ICES, which is funded by an annual grant from the Ontario Ministry of Health and Long-Term Care (MOHLTC). The opinions, results and conclusions reported in this paper are those of the authors and are independent from the funding sources. No endorsement by ICES or the Ontario MOHLTC is intended or should be inferred. Parts of this material are based on data and information compiled and provided by the Canadian Institute for Health Information ( $\mathrm{CIHI}$ ). However, the analyses, conclusions, opinions and statements expressed herein are those of the author, and not necessarily those of $\mathrm{CIHI}$. We thank IMS Brogan Inc. for use of their Drug Information Database.

Accepted: Nov. 14, 2019

Correspondence to: Chaim Bell, chaim.bell@sinaihealthsystem.ca 